\title{
MRS OFFICERS FOR 1983
}

The duties of MRS officers and councillors are enumerated in the Society's By-laws, and for your convenience are summarized here.

The President is the chairman of the council and its Executive Committee. Acting as the principal representative of and spokesman for the Society, the president guides the Society's development, its functions and services. One of the position's chief responsibilities is the appointment of members to committees. The president, alone among the Society's leadership, is not directly elected: the first vice president automatically assumes the position at the end of his one-year term.

The First Vice President acts for the president when the latter is unable to carry out his duties, and assumes the post if it becomes permanently vacant. Like the Second Vice President, he assists the president in the business of the Society.

The Secretary keeps the official minutes of meetings, maintains the records of the Society, conducts the annual election and carries on all of the Society's correspondence as directed by the president and the council.

The Treasurer acts as custodian of the Society's funds, maintains its financial records, receives its revenues and disburses its expenditures. The treasurer provides financial reports to the council at each of its meetings.

The Councillors direct the affairs and activities of the Society. The council meets formally at least three times a year, but the demands upon its members are much greater. Aside from committee work, they are consulted by the officers throughout the year as decisions affecting the MRS must be made.

Of the officers, all serve one-year terms except the secretary and treasurer, who serve for two years. Councillors serve three-year terms; five are elected each year.

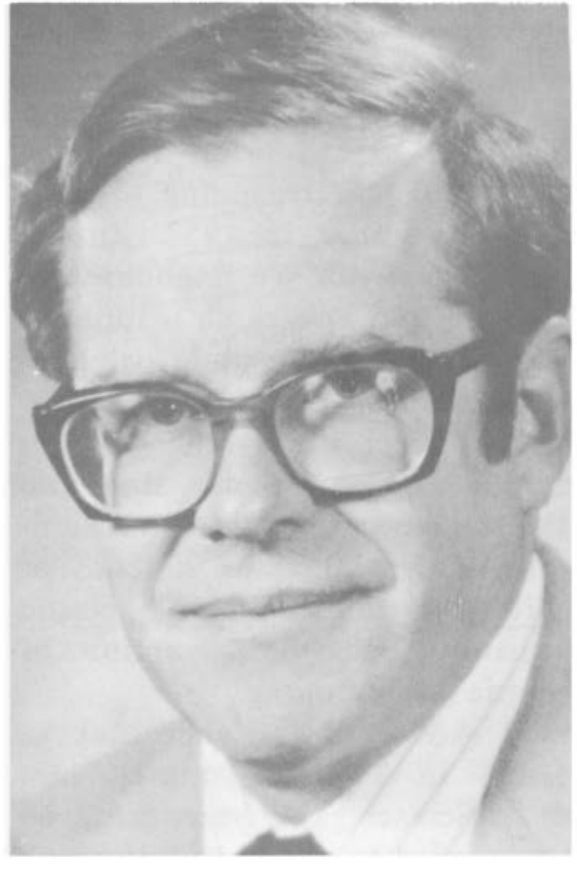

\section{C.W. White}

First Vice President

Oak Ridge National Laboratory

Oak Ridge, TN 37830

(615) 574-6295

C.W. White received his B.S. degree in physics from MIT in 1962 and his Ph.D. in physics from Duke in 1967. He joined the technical staff of Bell Labs, where he was involved in studies of low energy ion-surface and ion-atom collisions, surface physics, ion implantation and atomic physics.

In 1975 he joined the solid state division of Oak Ridge National Lab. His present research interests include laser annealing, ion implantation, ion beam surface layer analysis, surface physics and ion beam modification of materials.

A member of the MRS council for the past two years, White was a program committee member in 1981 and chairman of the publications committee in 1982.

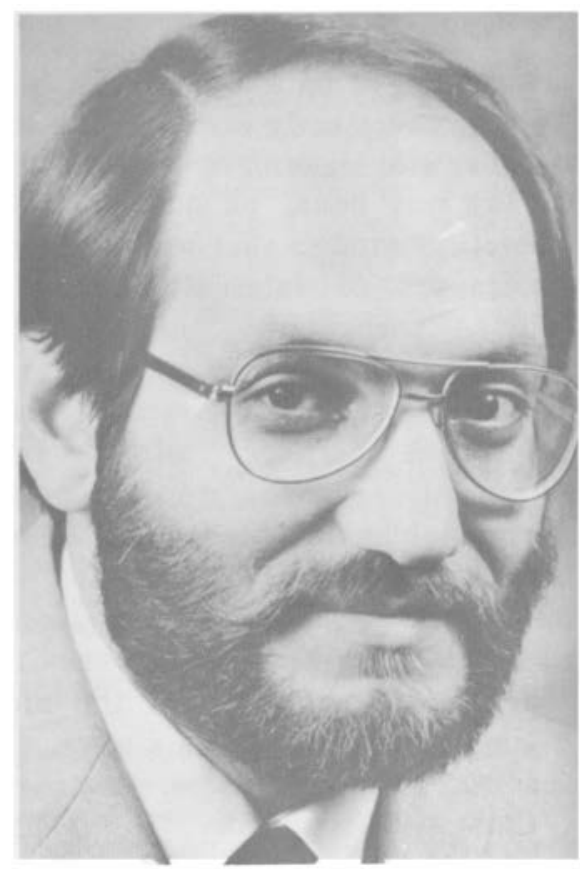

\section{Elton N. Kaufmann}

Second Vice President

Lawrence Livermore Laboratory

University of California

Livermore, CA 94550

(415) 422-1100

Kaufmann earned his B.S. from Rensselaer Polytechnic Institute and his Ph.D., also in physics, from the California Institute of Technology in 1968. He joined Bell Laboratoried, where he studied materials properties using hyperfine interactions, ion-solid interactions and laser-solid interaction techniques. In 1981 he joined the materials science division of the Livermore Lab, where currently he is studying the application of directed energy processing methods to materials.

Author of more than 80 technical publications, Kaufmann is editor of the journal Hyperfine Interactions. He is co-chairman of this year's annual meeting, and chairman of the MRS Corporate Participation Committee. 